\author{
Isabel Belo ${ }^{1}$ \\ Alicia García-Abuín ${ }^{2}$ \\ Diego Gómez-Díaz ${ }^{2}$ \\ José M. Navaza² \\ Isabel Vidal-Tato ${ }^{2}$ \\ ${ }^{1}$ University of Minho, \\ Department of Biological \\ Engineering - CEB, Chemical \\ and Biochemical Engineering \\ Group, Braga, Portugal. \\ ${ }^{2}$ University of Santiago de \\ Compostela, Department of \\ Chemical Engineering - ETSE, \\ PF\&PT and Ecoefficiency \\ Research Teams, Santiago de \\ Compostela, Spain.
}

\section{Research Article \\ Effect of Tween 80 on Bubble Size and Mass Transfer in a Bubble Contactor}

\begin{abstract}
Gas absorption in aqueous solutions with Tween 80 and absorption processes based on hydrodynamics and mass transfer is determined. The impact of surfactant concentration on gas holdup and gas-liquid interfacial area is analyzed, observing an increase of these parameters with surfactant concentration. The influence of liquid-phase contamination on the absorption process is investigated on the basis of the liquid-film mass transfer coefficient, removing the effect caused by the presence of a surfactant and the gas flow rate on the interfacial area and, thereby, on the volumetric mass transfer coefficient. The opposite effect on the mass transfer coefficient can be observed which decreases in the presence of the surfactant.
\end{abstract}

Keywords: Absorption, Interfacial area, Mass transfer coefficient, Surfactant

Received: March 11, 2011; revised: July 14, 2011; accepted: August 17, 2011

DOI: $10.1002 /$ ceat.201100140

\section{Introduction}

Several industrial processes are based on gas-liquid equipments and for this reason a suitable gas absorption rate is an important point in different chemical and biochemical processes which involve this kind of operation. The gas phase is commonly placed in the contactor by means of small bubbles in order to supply a high interfacial area and consequently an increase in mass transfer between the phases. The liquid phases commonly found in the chemical industry are very complex due to the operating conditions and presence of several compounds. Therefore, important research studies were performed to understand the influence of the liquid phase properties on the bubble formation phenomenon. Nevertheless, whilst the impact of the liquid density and viscosity was extensively studied, the liquid surface tension and its effects must be analyzed in gas-liquid contactors. Taking into account the results and conclusions concerning the effect of the liquid surface tension, its influence is not clearly separated from the effect caused by density and viscosity $[1,2]$.

In the last few years, several studies enhanced the knowledge about the absorption processes in systems involving the presence of surface-active substances. Several studies concluded that low concentrations of surface-active additives can affect gas-liquid mass transfer parameters such as the volumetric

Correspondence: Dr. D. Gómez-Díaz (diego.gomez@usc.es), University of Santiago de Compostela, Department of Chemical Engineering ETSE, Rúa Lope Gómez de Marzoa s/n, E-15786 A Coruña, Spain. mass transfer coefficient $\left(k_{\mathrm{L}} a\right)$ and/or mass transfer coefficient $\left(k_{\mathrm{L}}\right)[3,4]$. These studies concentrated on the influence of different operation variables on the global mass transfer and, more specifically, on gas holdup [5], bubble diameters and gas-liquid interfacial area [6], interfacial turbulence [7], and mass transfer coefficient [8]. Other researchers were interested in analyzing the influence of the surfactants' nature, taking into account the molecule sizes [9] as well as their ionic character [8].

Nowadays, surface agents in gas-liquid systems have reached great importance, mainly due to the presence of this kind of substances in bioreactors: (i) as product of the bioreaction (production of biosurfactants) [10], and (ii) as stabilizer substance in the two-phase partition bioreactors to maintain the emulsion formed in the liquid phase [11].

Here, the absorption process behavior in complex systems involving the use of a surfactant (Tween 80) commonly applied in numerous processes that imply gas-liquid mass transfer processes [12] such as fermentation operations in gas-liquid bioreactors, is investigated. The system employed in this study is analyzed taking into account hydrodynamic parameters (such as gas holdup, bubble diameter, and interfacial area) and mass transfer based on the determination of the mass transfer coefficient.

\section{Materials and Methods}

Tween 80 (nonionic surfactant) was supplied by Sigma-Aldrich (CAS No. 9005-65-6) with an average molecular weight of $1310 \mathrm{~g} \mathrm{~mol}^{-1}$. Carbon dioxide of $99.998 \%$ purity was from 
Carburos Metálicos (Spain). Tween 80 aqueous solutions were prepared with double-distilled water and using an analytical balance (Kern 770). The concentration of Tween 80 aqueous solutions varied from 0 to $1.2 \cdot 10^{-3} \mathrm{~mol} \mathrm{~L}^{-1}$.

Surface tension corresponding to aqueous solutions of Tween 80 was obtained using a Krüss K-11 tensiometer that works with the Wilhelmy plate method. The platinum plate used in this work was also supplied by Krüss. After each measurement, the plate was cleaned with water and acetone and flame-dried.

A square bubble column contactor was used to determine the carbon dioxide absorption rate to aqueous solutions of Tween 80 , as described in [13]. The contactor made of methacrylate had a side length of $6 \mathrm{~cm}$ and a height of $114 \mathrm{~cm}$. The volume of the bubble column was $3 \mathrm{~L}$. Carbon dioxide was fed to the bubble contactor through a gas sparger consisting of a glass capillary with only one orifice (internal diameter: $1.6 \mathrm{~mm}$ ). This sparger produced a low number of bubbles and allowed careful analysis of the influence of variables on the characteristics of the bubbles.

Pure carbon dioxide was employed as gas phase and this stream was passed through two humidifiers at $25^{\circ} \mathrm{C}$. This procedure was carried out to remove the resistance to mass transfer in the gas phase with the aim of quantifying the mass transfer coefficient corresponding to the liquid phase. Two mass flow controllers (5850 Brooks Instruments) were used to maintain a constant inlet gas flow rate and to measure it at the outlet. The mass flow controllers were calibrated by the supplier for operation conditions used in this work. Inlet and outlet stream pressures were determined by a Testo 512 digital manometer.

The influence of gas flow rate and liquid phase composition on gas holdup and gas-liquid interfacial area was determined and the absorption rate of carbon dioxide in aqueous solutions of Tween 80 was analyzed. The surfactant concentration in the liquid phase was varied from 0 to $1.22 \cdot 10^{-3} \mathrm{M}$, and three gas flow rates were applied $\left(18,30,40 \mathrm{~L} \mathrm{~h}^{-1}\right)$ to analyze the effect caused by this operation variable on the absorption process.

Bubble size distribution was determined by the analysis of different photographs taken at different heights in the bubble column by means of a Sony (DCR-PC330E) video camera. A minimum number of 100 well-defined bubbles were taken to obtain the bubble size distribution for each surfactant concentration and gas flow rate. The geometrical characteristic measurements corresponding to bubbles were performed with the Image Tool v3.0 software package.

The overall gas holdup was determined by means of the volume expansion method based on the measurement of the change on the aqueous phase level before and after gassing (Eq. (1)):

$\varepsilon_{\mathrm{G}}=\frac{\Delta V}{\Delta V+V_{\mathrm{L}}}$

where $V_{\mathrm{L}}$ is the ungassed liquid volume and $\Delta V$ is the change in the liquid volume.

The bubbles produced in this kind of liquid phases show an ellipsoid shape, thus implying the determination of major $(E)$ and minor $(e)$ axes of the projected ellipsoid (in two dimen- sions). Eq. (2) allows calculating the diameter of the equivalent sphere which is taken as the representative dimension.

$d=\sqrt[3]{E^{2} e}$

For this kind of systems, the Sauter mean diameter $\left(d_{32}\right)$ is recommended [14] and can be calculated using Eq. (3):

$d_{32}=\frac{\sum_{\mathrm{i}}\left(n_{\mathrm{i}} d_{\mathrm{i}}^{3}\right)}{\sum_{\mathrm{i}}\left(n_{\mathrm{i}} d_{\mathrm{i}}^{2}\right)}$

where $n_{\mathrm{i}}$ is the number of bubbles with an equivalent diameter $\left(d_{\mathrm{i}}\right)$.

Using the values for Sauter mean diameter and gas holdup determined for all experimental conditions, it is possible calculating the gas-liquid interfacial area by Eq. (4):

$a=\frac{6 \varepsilon_{\mathrm{G}}}{d_{32}\left(1-\varepsilon_{\mathrm{G}}\right)}$

\section{Results and Discussion}

The present work focuses on the effect caused by the presence of different concentrations of a surfactant in aqueous solution on the absorption process. Based on the analysis of the gas holdup and the gas-liquid interfacial area produced in the contactor, the hydrodynamic behavior is investigated. The influence of superficial gas velocity on gas holdup is illustrated in Fig. 1. It can be observed that an increase in the gas flow rate produces an increase in the gas holdup. This kind of behavior indicates that a change in the bubbling regime is not produced in the studied range. The bubbling regime is pseudo-homogeneous in all cases and, therefore, a coalescence process is not detected. The experimental data in Fig. 1 correspond to pure water (without Tween 80 addition) but the experiments developed with different surfactant concentrations do not show sig-

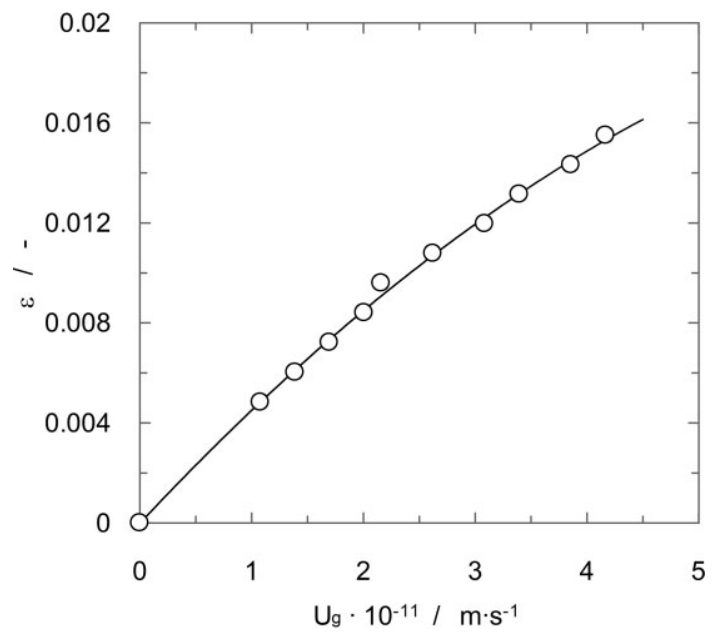

Figure 1. Effect of superficial gas velocity on gas holdup. 
nificant changes with regard to the values obtained for the carbon dioxide/water system, in agreement with other researches using different surfactants $[15,16]$.

The hydrodynamic characterization of the gas-liquid systems in the present work includes the analysis of the bubble size distribution produced in the bubble column. The bubble size distribution and gas holdup could be used for gas-liquid interfacial area determination. An example of bubble size distribution is presented in Fig. 2. This figure allows analyzing the influence of surfactant concentration on bubble size distribution. The experimental results indicate that a higher value in surfactant concentration produces a decrease in bubble size. This behavior is in agreement with the results obtained for systems with a short-chain-length surfactant $[6,9]$. Also, Fig. 2 indicates that an increase in surfactant concentration produces a narrower size distribution.

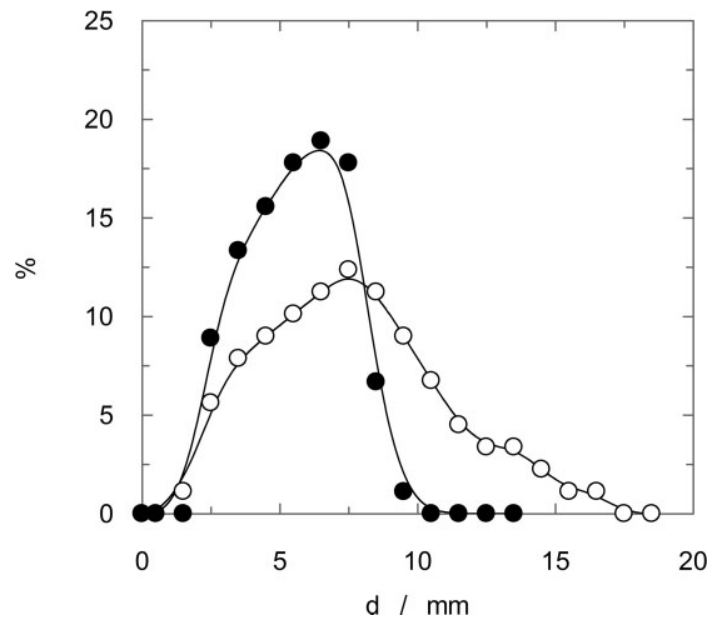

Figure 2. Influence of surfactant concentration on bubble size distribution. $Q_{\mathrm{g}}=30 \mathrm{Lh}^{-1}$. (O) $C_{\mathrm{s}}=1.46 \cdot 10^{-5} \mathrm{~mol} \mathrm{~L}^{-1}$, $C_{\mathrm{s}}=1.22 \cdot 10^{-3} \mathrm{~mol} \mathrm{~L}^{-1}$.

This behavior is due to the influence caused by the surfactant presence on the surface tension value. The surfactant produces a significant decrease in surface tension, thus affecting strongly the bubble size produced in the contactor. Fig. 2 displays the decrease observed in the bubble size distribution produced by the surfactant. Fig. 3 illustrates the influence of surfactant concentration on surface tension, indicating the important impact of low surfactant concentrations. The critical micelle concentration is calculated as $5 \cdot 10^{-5} \mathrm{~mol} \mathrm{~L}^{-1}$ (Fig. 3).

Using the bubble size distribution for each experimental condition and the gas holdup produced in the bubble column, the gas-liquid interfacial area is calculated by Eq. (3). Fig. 4 summarizes the determined data for the interfacial area under the experimental conditions analyzed in this work. An increase in interfacial area is observed when the solute concentration increases in the aqueous solution. This behavior is due to the presence of this solute which produces a decrease in the bubble size (vide supra) with no influence on the gas holdup.

On the basis of experimental data, it can be concluded that the most significant change in the value of interfacial area is

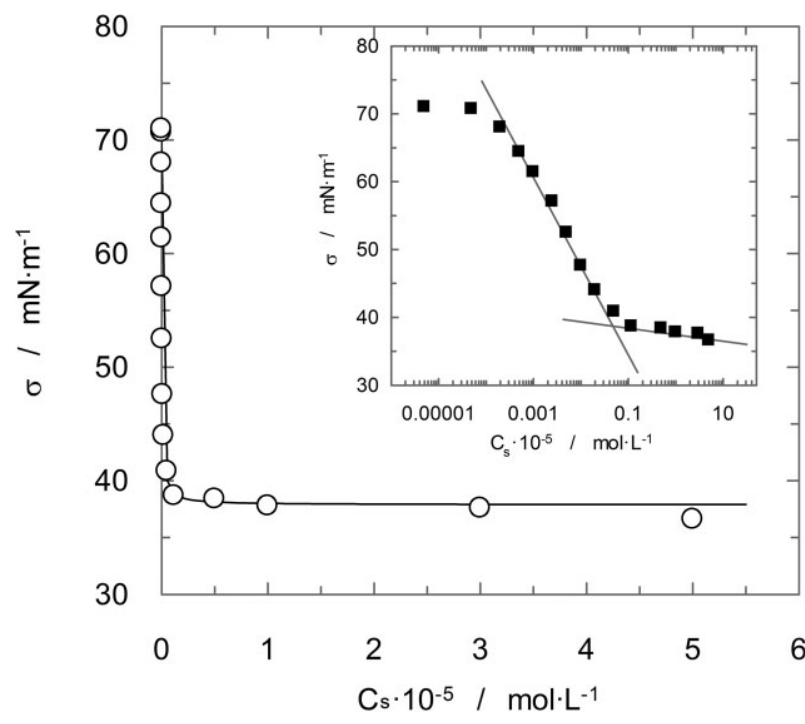

Figure 3. Influence of surfactant concentration on surface tension.

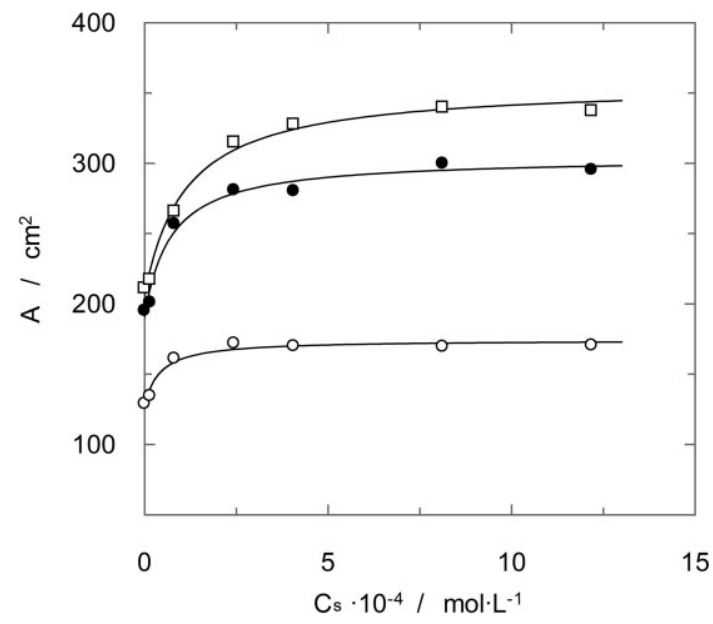

Figure 4. Influence of surfactant concentration and gas flow rate on gas-liquid interfacial area. (O) $Q_{g}=18 \mathrm{Lh}^{-1},(0) Q_{g}=30 \mathrm{Lh}^{-1}$, (口) $Q_{g}=40 \mathrm{Lh}^{-1}$.

caused by the addition of small quantities of surfactant. Higher surfactant concentrations than $0.03 \%$ produce practically constant interfacial areas with slight changes, in spite of the fact that important quantities of surfactant were added to the liquid phase. A similar behavior has been observed for other systems with surfactants in aqueous solutions $[8,17]$ and for all gas flow rates employed in this work. An increase in this value generates an increase in the interfacial area, although the reason is different to the one previously commented, when the surfactant concentration was varied. Regarding the gas flow rate effect, an increase in this variable does not cause significant changes in bubble size but an increase in gas holdup (see Fig. 1).

Gas-liquid interfacial area data determined under the different operation conditions could be fitted using an equation based on these variables (Eq. (5)). Different authors suggest 
the use of a similar equation taking into account the potential trend caused by these operation variables $[18,19]$.

$A=n_{1} C_{\mathrm{s}}^{\mathrm{n}_{2}} \mathrm{cmc}^{\mathrm{n}_{3}} Q_{\mathrm{g}}^{\mathrm{n}_{4}}$

where $C_{\mathrm{s}}$ is the surfactant concentration, $\mathrm{cmc}$ is the critical micelle concentration of Tween 80 , and $Q_{\mathrm{g}}$ is the gas flow rate.

Eq. (5) includes the surfactant concentration and the gas flow rate as important operation variables, but also the critical micelle concentration. This parameter provides information about the chain length and other properties related to hydrophobicity. Fig. 5 presents a comparison between the experimental and calculated values using a simple correlation (Eq. (5)). Only one surfactant is employed in this work, then the value of the critical micelle concentration is constant, but the expression used in Eq. (5) includes this value to preserve the equation general formulation. The use of the same equation allows comparing the value of the fit parameters with previous and future studies that use other surfactants. For comparison between experimental and calculated gas-liquid interfacial area under different experimental conditions a good agreement can be observed.

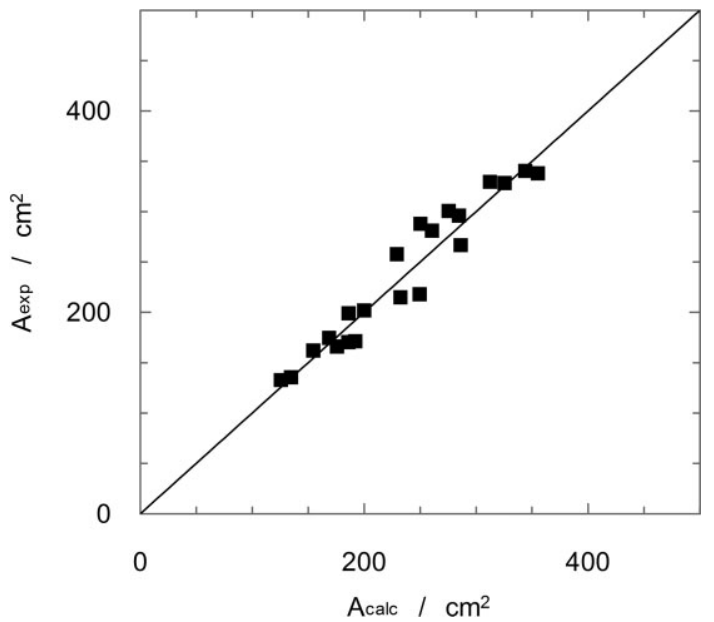

Figure 5. Comparison between experimental and calculated gasliquid interfacial area using Eq. (5).

The gas-liquid mass transfer corresponding to the absorption of carbon dioxide in Tween 80 aqueous solutions is also studied. The operation regime is semi-continuous, the liquid phase is placed into the contactor, and the gas phase is fed continuously to the bubble column. The obtained absorption kinetics data are employed to calculate the volumetric mass transfer coefficient. The mass transfer coefficient $\left(k_{\mathrm{L}}\right)$ is calculated taking into account the values of the volumetric mass transfer coefficient and the gas-liquid interfacial area. By this way, the influence of surfactant presence and concentration on mass transfer coefficient and gas-liquid interfacial area as well as the influence on each parameter individually could be analyzed.

Fig. 6 presents an example of the behavior of absorbed carbon dioxide concentration in the Tween 80 aqueous solutions. Being more specific, two experiments are compared in Fig. 6

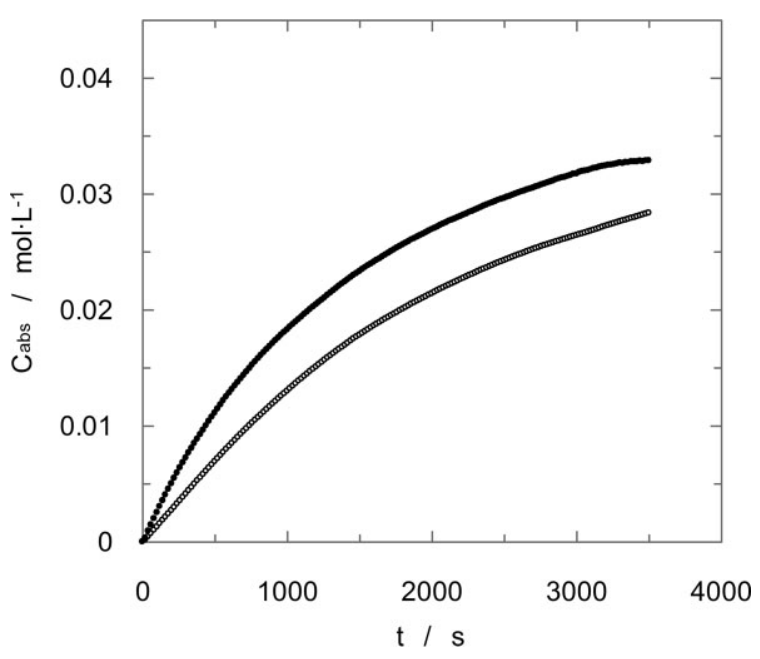

Figure 6. Effect of gas flow rate on carbon dioxide absorption data. $C_{\mathrm{s}}=4.1 \cdot 10^{-4} \mathrm{M}$. (○) $Q_{\mathrm{g}}=18 \mathrm{~L} \mathrm{~h}^{-1},(\bigcirc) Q_{\mathrm{g}}=40 \mathrm{Lh}^{-1}$.

using the same surfactant concentration and different gas flow rates. The experimental data indicate that an increase in the gas flow rate fed to the bubble column produces a higher increase in the carbon dioxide concentration, thus indicating that the mass transfer rate increases with the gas flow rate. This behavior is due to the fact previously commented, i.e., that an increase in the gas flow rate produces an increase in the interfacial area which, at the same time, generates an increase in the mass transfer rate.

Using the experimental data corresponding to the carbon dioxide absorption rate, the concentration of this substance in the liquid phase with time is calculated, and under the experimental regime (semi-continuous) the volumetric mass transfer coefficient can be determined by means of a gas phase mass balance via Eq. (6):

$\frac{\mathrm{d} C}{\mathrm{~d} t}=K_{\mathrm{L}} a\left(C^{\star}-C\right)$

where $C^{*}$ is the gas solubility, $C$ is the carbon dioxide concentration, and $K_{\mathrm{L}} a$ is the volumetric mass transfer coefficient. The diffusivity of carbon dioxide employed in this work is the same than the corresponding one for water [20] because the presence of a low Tween 80 concentration has no influence on this parameter. The use of a pure gas phase implies that the liquid side mass transfer coefficient is the same as the global mass transfer coefficient.

The same experimental procedure is carried out for the different experiments performed in the present work, and the volumetric mass transfer coefficient is calculated for each experimental condition. Fig. 7 illustrates the behavior and influence of different operation variables, such as gas flow rate and surfactant concentration. An important decrease in mass transfer coefficient is generated when small quantities of Tween 80 are added to the liquid phase, reaching a constant value of mass transfer coefficient independent of the surfactant concentration. This behavior is opposite to the previous one commented for the influence of surfactant concentration on the 


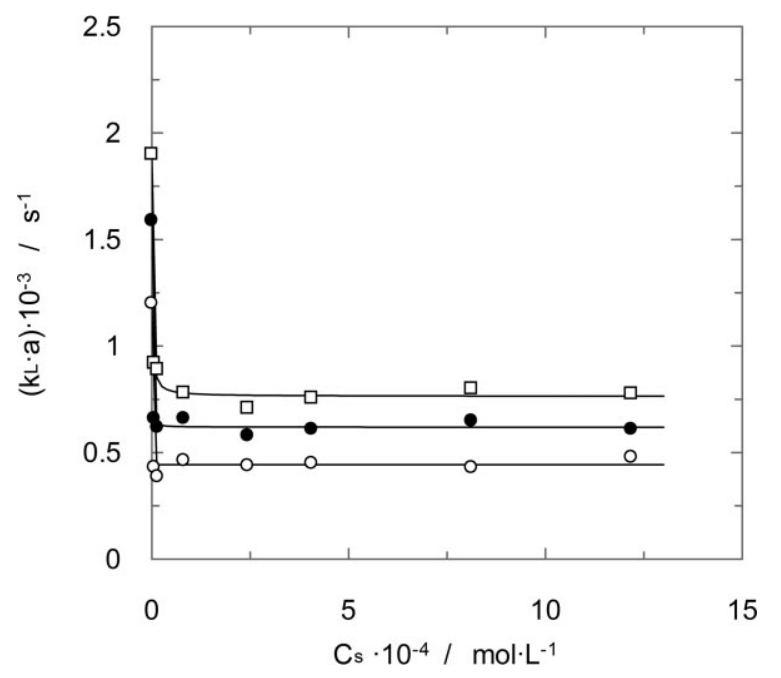

Figure 7. Influence of surfactant concentration and gas flow rate on volumetric mass transfer coefficient. (O) $Q_{g}=18 \mathrm{Lh}^{-1}$, $Q_{g}=30 \mathrm{Lh}^{-1},(\square) Q_{\mathrm{g}}=40 \mathrm{Lh}^{-1}$.

gas-liquid interfacial area (the increase of surfactant concentration produces an increase in interfacial area until a constant value). The effect of surfactant concentration on the interfacial area must be an increase in the volumetric mass transfer coefficient, however, the obtained behavior is the opposite. Taking this fact into account, the a-priori conclusion is that the presence of surfactant in the liquid phase has a significantly negative influence on the mass transfer coefficient, being higher than the positive effect on the interfacial area.

On the other hand, in relation to the influence of the gas flow rate fed to the bubble contactor, an increase of the volumetric mass transfer coefficient is observed when the gas flow rate increases. Taking into account the previously analyzed influence of the gas flow rate on the interfacial area and the results for the volumetric mass transfer coefficient, it can be concluded that the gas flow rate affects positively both parameters, i.e., mass transfer coefficient and interfacial area.

Using the experimental values of the volumetric mass transfer coefficient and the previously determined interfacial area, the mass transfer coefficient values for each experimental condition can be calculated by means of Eq. (7):

$k_{\mathrm{L}}=\frac{k_{\mathrm{L}} a}{a}$

The experimental data in Fig. 8 indicate a similar behavior like the volumetric mass transfer coefficient. A decrease in the mass transfer coefficient value is observed when low concentrations of surfactant are added to the liquid phase. Therefore, the results support the conclusions proposed a priori. The effect of the gas flow rate on the mass transfer coefficient (Fig. 8) indicates that this variable loses importance and that the same values of mass transfer coefficient at different gas flow rates are obtained. Similar results have been observed in previous studies that prove the non-influence of the gas flow rate on the mass transfer in this kind of contactors [3].

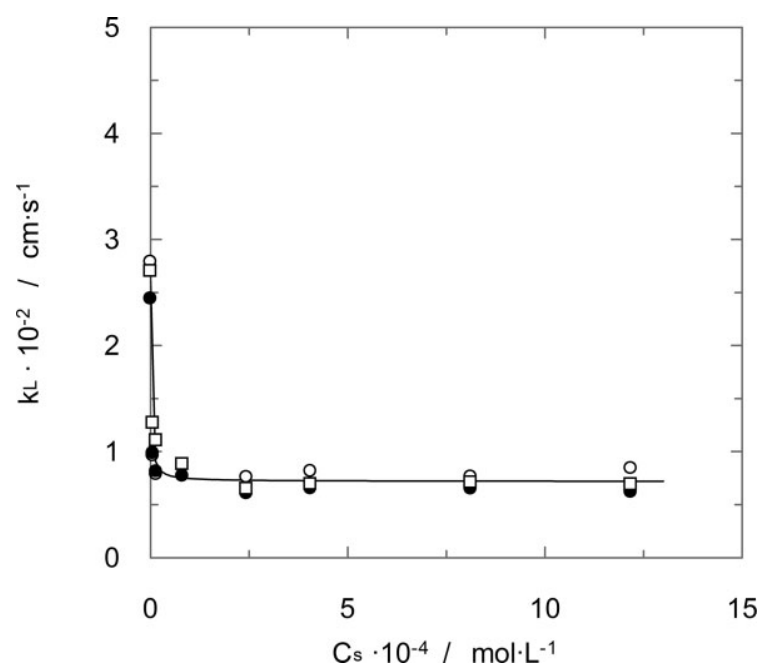

Figure 8. Influence of surfactant concentration on mass transfer coefficient. (○) $Q_{g}=18 \mathrm{Lh}^{-1},(\bigcirc) Q_{g}=30 \mathrm{Lh}^{-1},(\square) Q_{g}=40 \mathrm{Lh}^{-1}$.

Previous studies employing similar systems indicate that the presence of surfactant in the liquid phase reduces the mass transfer coefficient until a plateau for higher concentrations than the critical micelle concentration [3]. This reduction has been assigned to different reasons in relation to the increment in the transport resistance caused by the presence of surfactant molecules. The reduction in mass transfer rate is caused by different effects that act simultaneously: (i) reduction in gas diffusivity or (ii) decrease in turbulence near to the interface. A decrease in the driving force is produced that is directly related to the gas mass transfer rate to the liquid phase.

Other studies concluded that a low surfactant concentration produces an enhancement of mass transfer that generates an increase of the mass transfer coefficient $[21,22]$. In this work, this increase or enhancement is not observed and this behavior is assigned to the size of the surfactant molecule, compared to the experimental systems that indicate enhancement [23].

The decrease in the mass transfer coefficient by the presence of surfactant molecules in the liquid phase is assigned to different modifications caused by the accumulation of surfactant molecules at the gas-liquid interface. This accumulation provokes reduction in the renewal of the liquid elements and then decrease of the driving force. These effects produce a decrease in the mass transfer rate. Different studies [3] concluded that this reduction in the mass transfer rate is observed until the surfactant concentration reaches the value corresponding to the critical micelle concentration. When this concentration is reached, it is impossible to increase the surfactant concentration in a gas-liquid interface because the micelle formation already occurred.

For gas-liquid systems involving the presence of different quantities of surfactants in the liquid phase, a previous work has developed a model with a good behavior in the mass transfer coefficient determination and, taking into account the special changes produced by this kind of substance, in the dynamics of gas-liquid systems as well [8]. This model indicates that in the presence of surfactants the mass transfer coefficient could be included between $k_{\mathrm{L}}^{0}$ (mass transfer coefficient 
corresponding to a free surface $\left(S_{\mathrm{e}}=0\right)$ ) and $k_{\mathrm{L}}^{1}$ (corresponding value for a saturated surface $\left(S_{\mathrm{e}}=1\right)$ ). These limits are considered in Eq. (8):

$k_{\mathrm{L}}=S_{\mathrm{e}} k_{\mathrm{L}}^{1}+\left(1-S_{\mathrm{e}}\right) k_{\mathrm{L}}^{0}$

$k_{\mathrm{L}}^{0}$ (free surface) is calculated using the model developed by Higbie [24] whereas $k_{\mathrm{L}}^{1}$ (mass transfer coefficient corresponding to a saturated interface) is difficult to estimate because the influence of the kind of surface-active substance could play an important role. Sardeing et al. [8] suggest an equation that involves the Frössling equation [25] for mass transfer calculation and also the surfactant nature characteristics:

$k_{\mathrm{L}}^{1}=1.744 K^{-0.084} k_{\mathrm{L}}^{\text {Frössling }}$

where $K$ is the surfactant adsorption (at the gas-liquid interface) equilibrium constant. High values of this constant imply that the equilibrium is reached in a short time. When a clean bubble is produced in the column, the accumulation of surfactant at the gas-liquid interface occurs rapidly, and this process produces a decrease in mass transfer rate.

Fig. 9 illustrates the obtained behavior for the Higbie, Frössling, and Sardeing et al. (using Eq. (9)) models. The comparison with the experimental values of mass transfer coefficient (see Fig. 9) indicates that Higbie's model overestimates the values of mass transfer coefficients except for the system in the absence of the surfactant. On the other hand, Frössling's model provides lower values than the experimental ones. At a high surfactant concentration, the experimental values are closer to Frössling's model due to the increase in the surfactant concentration at the gas-liquid interface. The last model, developed by Sardeing et al., allows the calculation of the mass transfer coefficient with better results when compared with the experimental data. The values contributed by this last model when the surfactant concentration increases are very close to Frössling's model. The experimental data show a plateau with a constant value of mass transfer coefficient higher than the value calculated using Frössling's equation. Due to the behavior of Sardeing's model, a modification of this model is performed in this work, by means of changing the constant (1.744) of Eq. (9), since this value is related to the surfactant nature [8]. This constant is determined in the present study using the experimental data of mass transfer coefficient because the surfactant employed here is very different in molecular weight and size to the substances used in previous works that used this model. This fact could indicate that the model of Sardeing et al. does not take into account some factors related with the surfactant nature. Eq. (9) was modified, obtaining the expression of Eq. (10). This modification in the Sardeing et al. model allows fitting, with better results, the influence of Tween 80 concentration to the experimental values of mass transfer coefficient in comparison with the other models analyzed (see Fig. 9).

$k_{\mathrm{L}}^{1}=100 K^{-0.084} k_{\mathrm{L}}^{\text {Frössling }}$

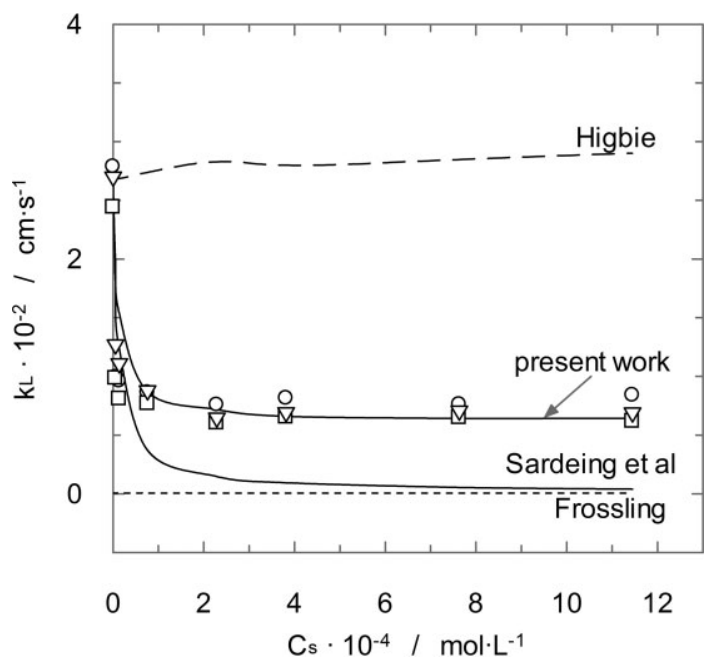

Figure 9. Comparison of mass transfer coefficient experimental values with different models. (O) $Q_{g}=18 \mathrm{~L} \mathrm{~h}^{-1},(\Theta) Q_{g}=30 \mathrm{~L} \mathrm{~h}^{-1}$, ( $\square) Q_{g}=40 \mathrm{Lh}^{-1}$.

\section{Conclusions}

The effect caused by the presence of Tween 80 on different parameters (gas holdup, bubble size distribution, interfacial area, and mass transfer coefficient) related to the mass transfer rate in a bubble column contactor is analyzed. The presence of this substance generates an important increase in gas-liquid interfacial area produced in the bubble column, caused by a significant decrease of the bubble diameter, because no influence of Tween 80 on the gas holdup is detected. On the other hand, an increase in the gas flow rate produces also an increase in interfacial area due to an increase in gas holdup.

The presence of Tween 80 causes the opposite effect on the mass transfer coefficient producing a strong decrease at a low surfactant concentration. The impact of the gas flow rate on the mass transfer coefficient is considered negligible.

A modification of Sardeing's model allows fitting the experimental data, taking into account the values corresponding to mobile or rigid bubbles and the special characteristics of Tween 80 in relation to its surface activity.

\section{Acknowledgment}

Diego Gómez-Díaz acknowledges the "Ramón y Cajal" position to the Ministerio de Ciencia e Innovación.

The authors have declared no conflict of interest.

\section{References}

[1] J. L. Liow, N. B. Gray, Chem. Eng. Sci. 1998, 43, 3129.

[2] K. Terasaka, H. Tsuge, Chem. Eng. Sci. 1993, 46, 3417. 
[3] J. M. T. Vasconcelos, J. M. L. Rodrigues, S. C. P. Orvalho, S. S. Alves, R. L. Mendes, A. Reis, Chem. Eng. Sci. 2003, 58, 1431.

[4] P. Painmanakul, K. Loubière, G. Hébrard, M. Mietton-Peuchot, M. Roustan, Chem. Eng. Sci. 2005, 60, 6480.

[5] M. C. Ruzicka, M. M. Vecer, S. Orvalho, J. Drahoš, Chem. Eng. Sci. 2008, 63, 951.

[6] K. Loubière, G. Hébrard, Chem. Eng. Process. 2004, 43, 1361.

[7] J. K. Kim, J. Y. Jung, J. H. Kim, M.-G. Kim, T. Kashiwagi, Y. T. Kang, Int. J. Refrig. 2006, 29, 170.

[8] R. Sardeing, P. Painmanakul, G. Hébrard, Chem. Eng. Sci. 2006, 61, 6249.

[9] D. Gómez-Díaz, J. M. Navaza, B. Sanjurjo, Ind. Eng. Chem. Res. 2009, 48, 5894.

[10] L. R. Rodrígues, J. A. Teixeira, R. Oliveira, Biochem. Eng. J. 2006, 32, 135.

[11] E. Dumont, H. Delmas, Chem. Eng. Process. 2003, 42, 419.

[12] N. Gomes, M. Aguedo, J. M. Teixeira, I. Belo, Biochem. Eng. J. 2007, 35, 380.

[13] D. Gómez-Díaz, J. M. Navaza, B. Sanjurjo, Chem. Eng. J. 2008, 144, 379.
[14] S.-Q. Zheng, Y. Yao, F.-F. Guo, R.-S. Bi, J.-Y. Li, Chem. Eng. Sci. 2010, 65, 5264.

[15] D. Gómez-Díaz, N. Gomes, J. A. Teixeira, I. Belo, Chem. Eng. J. 2009, 152, 354.

[16] K. Tadakamalla, K. V. Marathe, Desalination 2011, 266, 98.

[17] M. Rosu, A. Schumpe, Chem. Eng. Sci. 2007, 62, 5458.

[18] S. K. Majumder, G. Kundu, D. Mukherjee, Chem. Eng. J. 2006, $122,1$.

[19] E. J. Molga, K. R. Westerterp, Ind. Eng. Chem. Res. 1997, 36, 622.

[20] M. M. Sharma, P. V. Danckwerts, Chem. Eng. Sci. 1963, 18, 729.

[21] D. Gómez-Díaz, J. M. Navaza, B. Sanjurjo, Ind. Eng. Chem. Res. 2009, 48, 2671.

[22] A. Kaya, A. Schumpe, Chem. Eng. Sci. 2005, 60, 6504.

[23] A. García-Abuín, D. Gómez-Díaz, J. M. Navaza, B. Sanjurjo, Chem. Eng. Sci. 2010, 65, 4484.

[24] R. Higbie, Trans. Am. Inst. Chem. Eng. 1935, 31, 365.

[25] N. Frössling, Gerlands Beiträge zur Geophysik 1938, 52, 170. 